\section{Building a Promising Future for IUPAC}

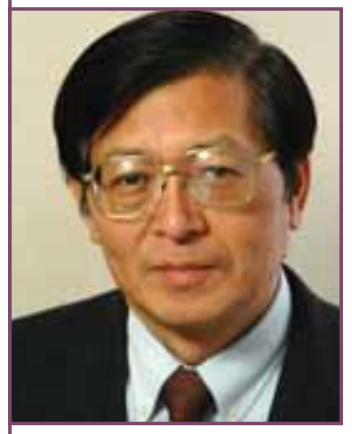

\author{
by Kazuyuki Tatsumi
}

A $s$ this is my first contribution to this column, I would like to outline my view of the future prospects for the roles and activities of IUPAC. As the only nongovernmental organization with a global membership of chemical societies, and as one of the world's foremost organizations for science, IUPAC bears significant responsibility for aiding the chemistry community in strengthening its expertise for the benefit of society worldwide.

I look forward to building a promising future for IUPAC as it advances the worldwide role of chemistry through excellence in science and innovative technology. We have so much to offer, with the participation of talented chemists from all over the world, the possibilities are endless. Next year, we celebrate the International Year of Chemistry, and are looking forward to many events that will lift the visibility and reputation of IUPAC. For one thing, we expect to recruit fresh ideas and enthusiasm from the next generation into the field of chemistry. For another, the IYC2011 is expected to provide a wonderful opportunity to strengthen the link between IUPAC and chemical societies throughout the world.

The momentum, which the IYC2011 will create, must be carried over to the next step. We must plan to make the most of the platform that this auspicious year of celebration will give us for promoting the importance of chemistry for addressing the world's most pressing needs. I would like to point out here that IUPAC will soon be looking forward to celebrating its centennial in 2019. This is not the distant future. It is not too early to start planning for the 100th anniversary of IUPAC, and I plan to pave the way.

As an organization that draws a community of expert chemists together from all over the world, we have a responsibility to use our resources to address global needs. For instance, there is international demand for alternative ways to create reliable energy such as solar and wind power. Don't chemists have the knowledge and potential to develop long-term energy solutions that are not only reliable but also sustainable? As governments and corporations look for efficient and sustainable ways to supply the energy needs of consumer societies, are we not in a unique position to help provide breakthroughs?

I am optimistic about the future of IUPAC, and yet a bright future is always a hard-earned one. We have witnessed the recent reforms of IUPAC structures, functions, and governance. This encouraging movement owes much to the dedication of successive presidents, officers, and active members, and I will continue to support innovative transformation of the Union. At the same time, the improvement of operational efficiency must be balanced with an increase in enthusiasm and devotion among members toward IUPAC activities. An important role of IUPAC is to facilitate discussion and networking between academia and industry. The activities of CHEMRAWN and $\mathrm{COCl}$ are good examples of IUPAC creating space for academia and industry to meet and discuss important issues and ideas. We need to continue to encourage and develop these and other initiatives that bring the academic world and the industrial world together.

Perhaps it is time for IUPAC to examine the key emerging issues in chemistry and modern society. We need to identify the priority areas for future commitments and new initiatives. Strategic planning is very important for an organization that wants to make the most of the opportunities that are available to it. Perhaps it is time for IUPAC to start thinking strategically about the future.* What are our goals for the next 5 years, or the next 10 years? Where are we heading? Without a clear concept of how we have grown and how we want to grow in the future we will be simply blown by the winds of the moment rather than directing our organization on a desired path. Over the years, IUPAC has grown and adapted to the perceived needs of chemistry. Let us direct our path to continue to address the current needs of the world community through the development of chemistry.

Kazuyuki Tatsumi <i45100a@nucc.cc.nagoya-u.ac.jp> has been vice president of IUPAC since January 2010. He served as vice president (2004-2007) and president (2008-2009) of the Inorganic Chemistry Division. Tatsumi is a professor at Nagoya University and has been a member of the Science Council of Japan (NAO for Japan) since 2008.

${ }^{*}$ The IUPAC Strategic Plan was last revised in 2002-2003; see http://media.iupac.org/news/archives/2002/strategic-plan.html. The IUPAC biennial report is prepared following the long-range goals detailed in the plan. 